\title{
X-Ray Powder Diffraction Analysis of Three Portland Cement Reference Material Clinkers
}

Paul E. Stutzman

Building and Fire Research Laboratory

Gaithersburg, Maryland 20899

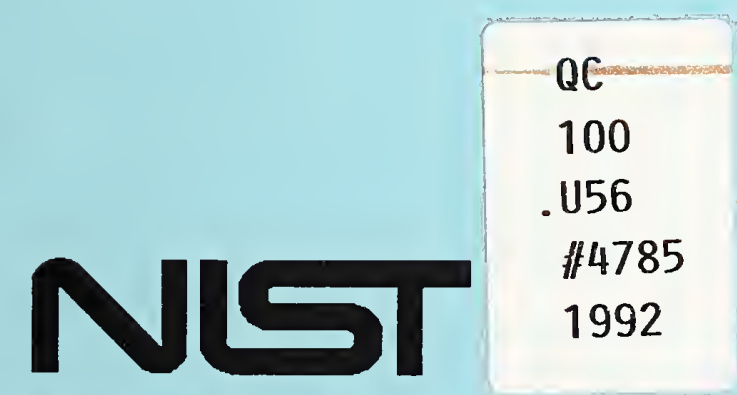

United States Department of Commerce Technology Administration

National Institute of Standards and Technology 



\section{X-Ray Powder Diffraction Analysis of Three Portland Cement Reference Material Clinkers}

Paul E. Stutzman

April 1992

National Institute of Standards and Technology

Gaithersburg, MD 20899

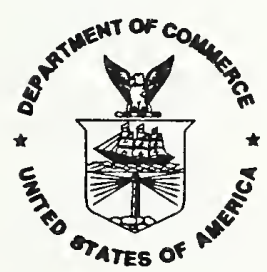

U.S. Department of Commerce Barbara Hackman Franklin, Secretary

Technology Administration

Robert M. White, Under Secretary for Technology

National Institute of Standards and Technology

John W. Lyons, Director 



\section{ABSTRACT}

Three portland cement clinker Reference Materials (RMs) are now available from the National Institute of Standards and Technology (NIST). They are intended for use in testing and developing methods for quantitative phase abundance analysis and have been selected as representative of the range of compositions and textures of North American clinkers.

Quantitative X-ray powder diffraction analysis was used to determine the phase abundance composition and compositional variability of eight randomly selected samples from each RM. In addition, each sample was split for duplicate analyses for evaluation of intra-sample phase abundance variability. The Reference Intensity Ratio method was used for powder diffraction calibrations and quantitative analysis. Both pure-phase standards and subsamples of the RM clinkers, which were point counted using the scanning electron microscope, were used for calibrations. Phase abundance values generally agree with those reported in earlier studies and the inter-sample standard deviation values were generally less than or equal to the intra-sample standard deviation values.

KEYWORDS: Cement clinker; composition; optical microscopy; quantitative analysis; reference materials; scanning electron microscopy; X-ray powder diffraction. 
Page

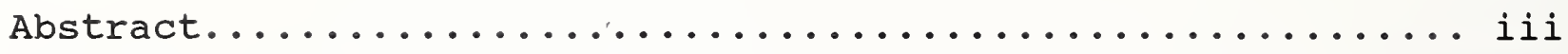

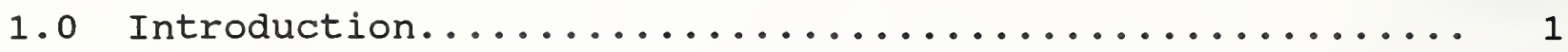

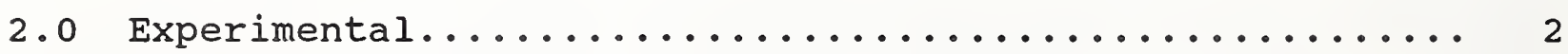

2.1 Sampling and Sample Preparation.............. 2

2.2 Scanning Electron Microscopy (SEM)

of Polished Sections...................... 3

2.3 Salicylic Acid and Methanol Extraction (SAM)..... 3

$2.4 x$-Ray Powder Diffraction................... 5

2.4.1 The Internal standard or Reference Intensity

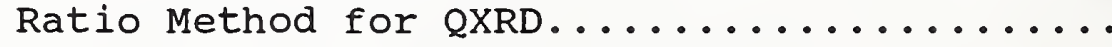

2.4.2 Selection of an Internal standard....... 8

2.4.3 Clinker Calibration Standards.......... 8

2.4 .4 Determination of RIR Values........... 10

2.4 .5 QXRD of the RM Clinkers............ 11

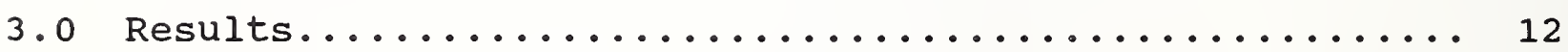

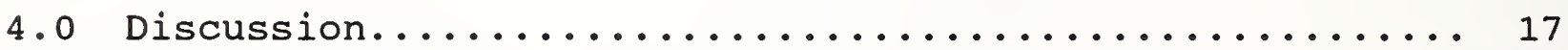

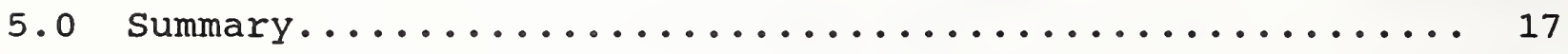

6.0 Acknowledgements......................... 17

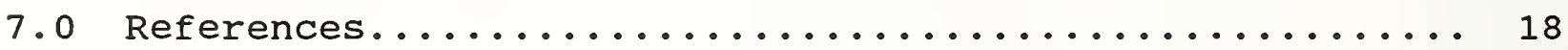


Table 1. Phase abundances as determined by reflected

$\underline{\text { Page }}$ white-light microscopy, expressed as mass

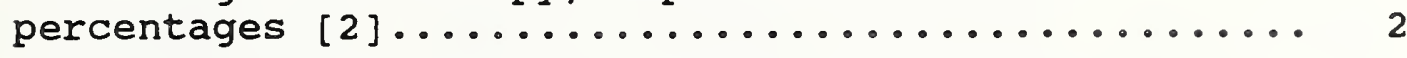

Table 2. Mass percent phase abundance and probable error of SEM point counts for RIR calibrations............ 10

Table 3. Reference Intensity Ratios (I/I $I_{\mathrm{Si}}$ ) as calculated from the RM clinkers and pure phases. Some peaks used only pure phase RIRs (P); blanks indicate peaks not measured for that analysis.............

Table 4. QXRD Data from replicate scans of sample 1, split A from RM 8486, without repacking the powder (a) and replicate scans after repacking the powder for each scan (b). Weight percent values in (a) reflect peak intensity variations resulting from data collection and processing while (b) additionally includes variations due to sample heterogeneity and particle

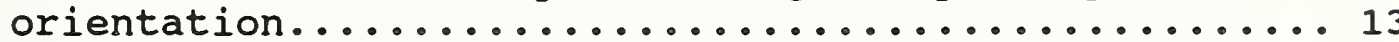

Table 5. QXRD data for Reference Material clinker 8486 with optical microscopy point count (OM) and QXRD data from [2], QXRD data from [17], and an earlier SEM point count of one sample [18]. Sample designation $31 \mathrm{~A}$ indicates $\mathrm{RM}$ set $\underline{3}$, sample $\underline{1}$, and duplicate $\underline{\mathbf{A}} \ldots 14$

Table 6. QXRD data for Reference Material Clinker 8487, with optical microscopy point count (OM) and QXRD data from [2], QXRD data from [17], and an earlier SEM point count of one sample $[18] \ldots \ldots \ldots \ldots \ldots \ldots \ldots$

Table 7. QXRD data for Reference Material Clinker 8488, with optical microscopy point count (OM) and QXRD data from [2], QXRD data from [17], and an earlier SEM point count of one sample $[18] \ldots \ldots \ldots \ldots \ldots \ldots \ldots$

\section{List of Figures}

Figure 1. Particle size distribution data of powders ground in a micronizing mill (a) and a ring an puck mill (b) ..

Figure 2. X-ray powder diffraction patterns from RMs 8486 ,

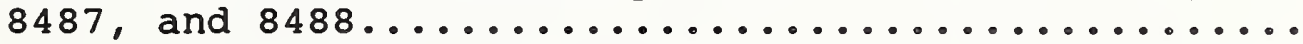

Figure 3. Profile fitting for the determination of backgroundsubtracted peak areas for labeled peaks of the silicon internal standard, $C_{3} S, C_{2} S, C_{3} A$, and $C_{4} A F \ldots$ 



\subsection{INTRODUCTION}

Advances in cement and concrete technology are based in the increased knowledge of their materials science. Reliable, practical techniques are needed for the characterization of concrete materials as necessary for understanding and predicting their performance. Portland cement is composed of an interground mixture of clinker and gypsum. Clinker is produced by firing a ground mixture of limestone and shale to about $1500^{\circ} \mathrm{C}$ where, after partial fusion, calcium silicates, calcium aluminates, and calcium aluminoferrites are formed. Phase abundance and texture of the clinker reflects the preparation, proportioning and firing of the raw materials and influences the performance and durability of the final product, the cement. This paper addresses the quantitative phase abundance analysis of cement clinker by $x$-ray powder diffraction.

Phase abundance composition can be estimated from chemical analysis data by using the Bogue equation. But, errors occur with the Bogue calculation because the chemical compositions of clinker phases can vary somewhat from the compositions assumed in the equations [1]. Methods for characterization of clinker microstructure and phase abundance include optical microscopy, X-ray powder diffraction, and scanning electron microscopy (SEM). Until recently, no reference material (RM) for phase abundance analysis of cement clinkers had been available.

Three RM clinkers have been produced in a joint effort by the Standard Reference Materials Program at the National Institute of standards and Technology (NIST) and construction Technology Laboratories (CTL) $[2,3]$. These clinkers represent the range of North American clinker production with respect to phase abundance, crystal size, and distribution and are intended for the testing and development of methods of quantitative phase abundance analysis of cement clinker.

To certify the phase abundance values in these clinkers, it was necessary to assess the intra- and inter-sample variability, and the purpose of this study was to determine these variabilities. Data already obtained using optical microscopy (Table 1) were not suitable for certifying phase abundance or for assessing sample variability because optical microscopy is not a bulk analytical technique. Quantitative X-ray powder diffraction analysis (QXRD), on the other hand, is a bulk analytical technique. Therefore this study examined the phase abundance composition of a set of randomly selected samples from each RM clinker using QXRD. Analysis of the data provided by this study may result in the certification of the clinker RMs and their reclassification as standard Reference Materials. 
Table 1. Phase abundances as determined by reflected white-light microscopy, expressed as mass percentages $[2,3]$.

\begin{tabular}{||l|l|l|l||}
\hline PHASE & RM 8486 & RM 8487 & RM 8488 \\
\hline Alite, C3S & 58.47 & 73.39 & 64.97 \\
\hline Belite, C, & 23.18 & 7.75 & 18.51 \\
\hline Aluminate, C3A & 1.15 & 12.09 & 4.34 \\
\hline Ferrite, CAF & 13.68 & 3.27 & 12.12 \\
\hline Free Lime, CaO & 0.18 & 2.45 & 0.00 \\
\hline Periclase, Mgo & 3.21 & 0.09 & 0.05 \\
\hline Alkali sulfate & 0.14 & 0.98 & 0.03 \\
\hline
\end{tabular}

Abbreviated notations for cement clinker phases commonly used in cement and concrete literature are used here, with $\mathrm{C}$ for $\mathrm{CaO}, \mathrm{A}$ for $\mathrm{Al}_{2} \mathrm{O}_{3}, \mathrm{~F}$ for $\mathrm{Fe}_{2} \mathrm{O}_{3}$, and $\mathrm{S}$ for $\mathrm{SiO}_{2}$. Therefore alite is designated $\mathrm{C}_{3} \mathrm{~S}$, belite is $\mathrm{C}_{2} \mathrm{~S}$, aluminate is $\mathrm{C}_{3} \mathrm{~A}$, and ferrite is $\mathrm{C}_{4} \mathrm{AF}$. Formulas for periclase (MgO) and free lime (CaO) are not abbreviated.

\subsection{EXPERIMENTAL}

\subsection{Sampling and Sample Preparation}

Samples were drawn from the packaged NIST clinker RMs. Each RM set is stored in three boxes, three flats deep. The packaged clinker RMs for analysis were selected using a random, stratified sampling scheme by specifying the flat, row, and column locations by computer-generated random numbers. About $50 \mathrm{~g}$ of each clinker was also sampled from bulk storage containers of reserve material.

Careful sample preparation and handling is important for quantitative $\mathrm{x}$-ray diffraction analysis. Since cement clinker phases such as free lime ( $\mathrm{CaO}$ ) can be altered by exposure to air, the powdered samples must be stored in a vacuum desiccator. Each clinker sample (about 10 grams) was split providing duplicates, which were ground to moderate fineness (about $-150 \mu \mathrm{m}$ ) with a mortar and pestle, and then wet ground for 18 minutes in $a$ micronizing mill, using $10 \mathrm{ml}$ of absolute ethanol as a grinding

${ }^{1}$ McCrone Micronizing mill, McCrone Research, Westmont, IL

${ }^{2}$ Mention of brand names is made to provide complete details of the experimental procedure. In no case does such identification imply recommendation or endorsement by the National Institute of standards and Technology, nor does it imply that the products are the best available for the purpose. 
aid. Wet grinding is preferable to dry grinding because it reduces the possibility of sample damage during the grinding operation [4].

Finely powdered samples ( $1 \mu \mathrm{m}$ to $10 \mu \mathrm{m}$ ) minimize QXRD problems such as sample homogeneity, preferred orientation, extinction, and microabsorption [5]. Particle size distribution data (Figure 1) indicate that the grinding procedure used here produces powders in which 99 percent of the particles are finer than $7 \mu \mathrm{m}$ and only 8 percent of the particles are finer than $0.5 \mu \mathrm{m}$ (Figure 1a). In comparison, grinding these clinkers in a ring-and-puck mill (both wet and dry grinding) produced powders with a maximum of only 73 percent of the material finer than $10 \mu \mathrm{m}$ and the finest particles being approximately $0.5 \mu \mathrm{m}$ (Figure 1b).

Wet grinding for longer than 20 minutes resulted in sample degradation, as evidenced by less intense, broader diffraction peaks. This phenomenon has been observed by Klug and Alexander [5] and was attributed to layers of amorphous material on the particle surfaces as a result of excessive grinding. While the peak areas may not change with this broadening, the overlapping peaks will be more difficult to resolve and weak intensity peaks may be more difficult to separate from the background.

\subsection{Scanning Electron Microscopy (SEM) of Polished Sections}

Samples $(25 \mathrm{~g})$ from the homogenized, reserve material for each RM clinker were split providing a subsample for SEM analysis and X-ray powder diffraction analysis. Two polished sections were examined by backscattered electron imaging and point counted to determine phase abundance composition. The X-ray diffraction (XRD) subsample was prepared using procedures provided later in this paper.

\subsection{Salicylic Acid and Methanol Extraction (SAM)}

The matrix phases in clinker can be concentrated by SAM extraction, where $\mathrm{C}_{3} \mathrm{~S}$ and $\mathrm{C}_{2} \mathrm{~S}$ and $\mathrm{CaO}$ are dissolved. The remaining material is comprised of $\mathrm{C}_{4} \mathrm{AF}, \mathrm{C}_{3} \mathrm{~A}, \mathrm{MgO}$, and alkali sulfates $[2,3]$. The concentration of these phases facilitates their identification by $\mathrm{XRD}$ and, when done quantitatively, can be used as another method for determination of total silicate and CaO abundance. The SAM extraction procedure involves the following steps from $[2,3]$ :

(1) preparation of the SAM solution at $1.0 \mathrm{~g}$ of salicylic acid per $5 \mathrm{ml}$ of methanol.

(2) 5-10 g of powdered clinker sample is added to $300 \mathrm{ml}$ of SAM solution in a $500 \mathrm{ml}$ Erlenmeyer flask, methanol is then added to increase the volume to $500 \mathrm{ml}$ and the flask is capped. 


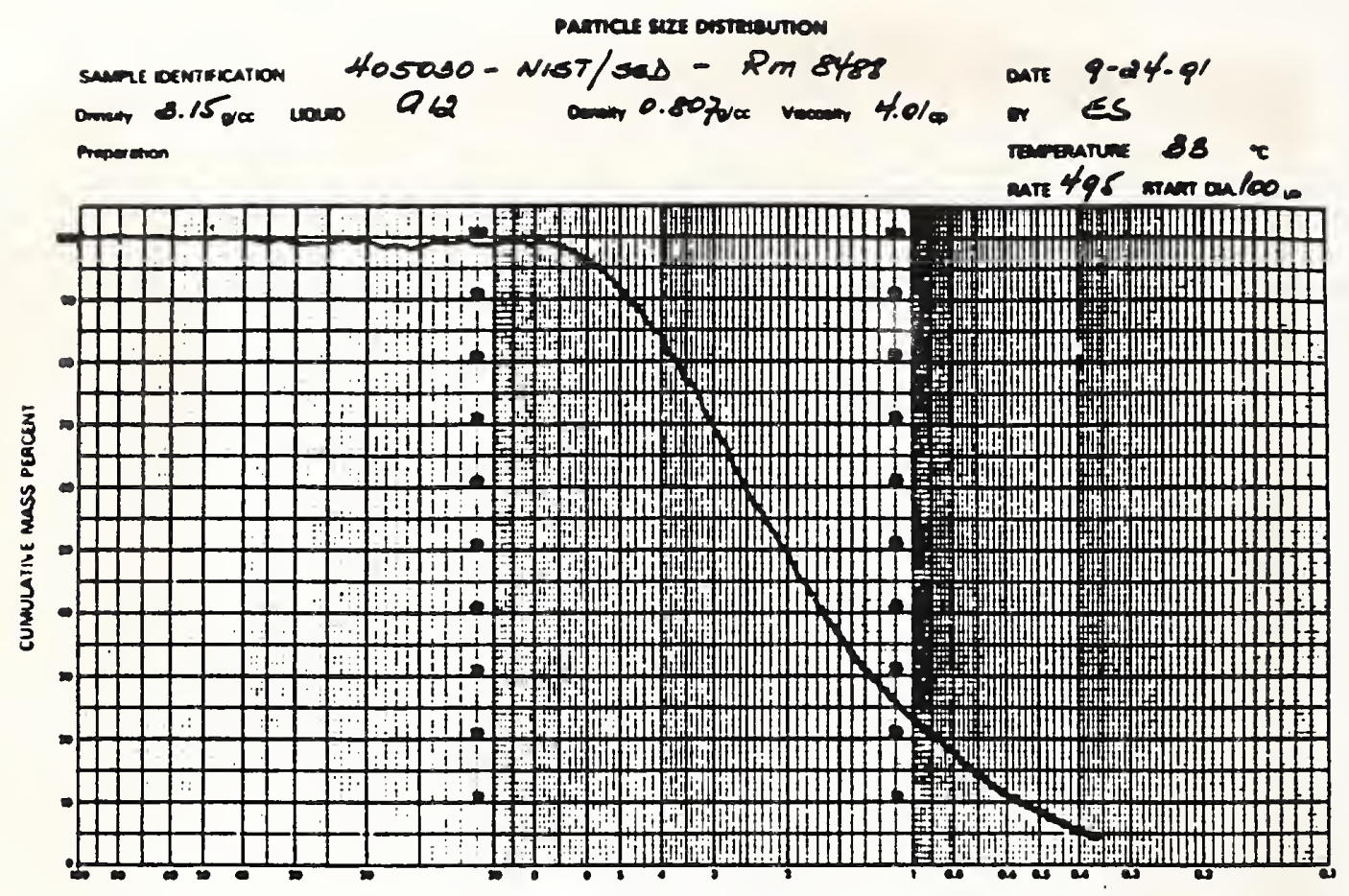

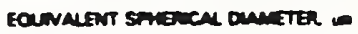

(a)

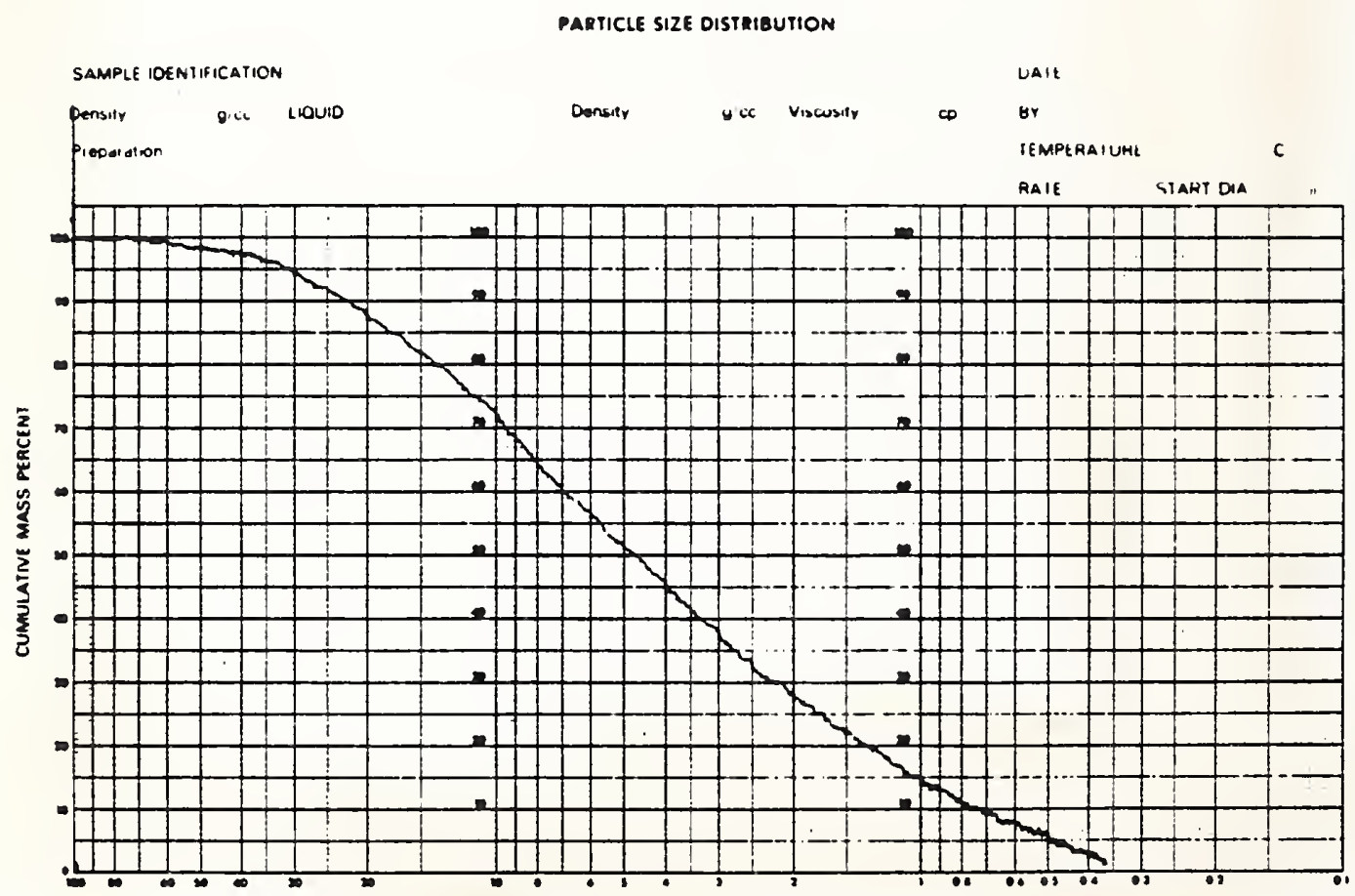

EOUIVALENT SPMERICAL OMAMETER

(b)

Figure 1. Particle size distribution data of powders ground in a micronizing mill (a) and a ring-and-puck mill (b). 
(3) stir the solution for one hour using a magnetic stirring bar, then allow to settle for 15 minutes.

(4) the supernatant is vacuum filtered through a pre-weighed $11 \mathrm{~mm}$ diameter Whatman No. 50 filter using a ceramic Buchner funnel and a filter flask. The remaining solids and liquid are poured onto the filter paper, washed with about $250 \mathrm{ml}$ of methanol, and vacuumed dry.

(5) the residue and paper are weighed, the insoluble residue percentage is calculated, and the sample is placed in a sealed glass vial for storage.

\subsection{X-Ray Powder Diffraction}

An automated Philips X-ray powder diffractometer with sample changer was used for data collection. The system operates at $45 \mathrm{kV}$ and $35 \mathrm{~mA}$ using copper $\mathrm{K} \alpha$ radiation, a variable divergence slit, $0.02^{\circ}$ receiving slit, diffracted beam monochromater, and a scintillation detector. The diffraction data are processed by personal computer for phase identification, peak profile fitting, and quantitative analysis. Examples of a portion of the powder diffraction patterns of the RM clinkers (Figure 2) show differences in peak intensities reflecting the differences in phase abundances.

Identification of polymorphs of the individual phases in a bulk clinker sample can be difficult because of the large number of overlapping peaks and similarity of the patterns [1]. Monoclinic $\mathrm{C}_{3} \mathrm{~S}$ is the predominant polymorph in each of the clinkers, although RMs 8486 and 8487 appear to also contain triclinic $C_{3}$ S.

SEM examination of RMS 8486 and 8488 revealed the presence of cubic and some orthorhombic $\mathrm{C}_{3} \mathrm{~A}$. The cubic variety is identified by its fine-grained, equant crystals, and the orthorhombic variety by its lath-shaped crystals [1]. However, the matrix of RM 8487 was too fine-grained for the observation of individual $C_{3} \mathrm{~A}$ crystals.

Diffraction data of SAM residues did not clearly indicate the presence of orthorhombic $\mathrm{C}_{3} \mathrm{~A}$ in $\mathrm{RM}$ 8487. Because the cubic polymorph is predominant in the other SAM residues cubic RIRs were used for analysis of $\mathrm{C}_{3} \mathrm{~A}$.

Inherent problems of QXRD include sample preparation, particle size of the powder, sample heterogeneity, sample absorption effects, preferred orientation, accurate calibrations, and consistent analysis of the diffraction data. 


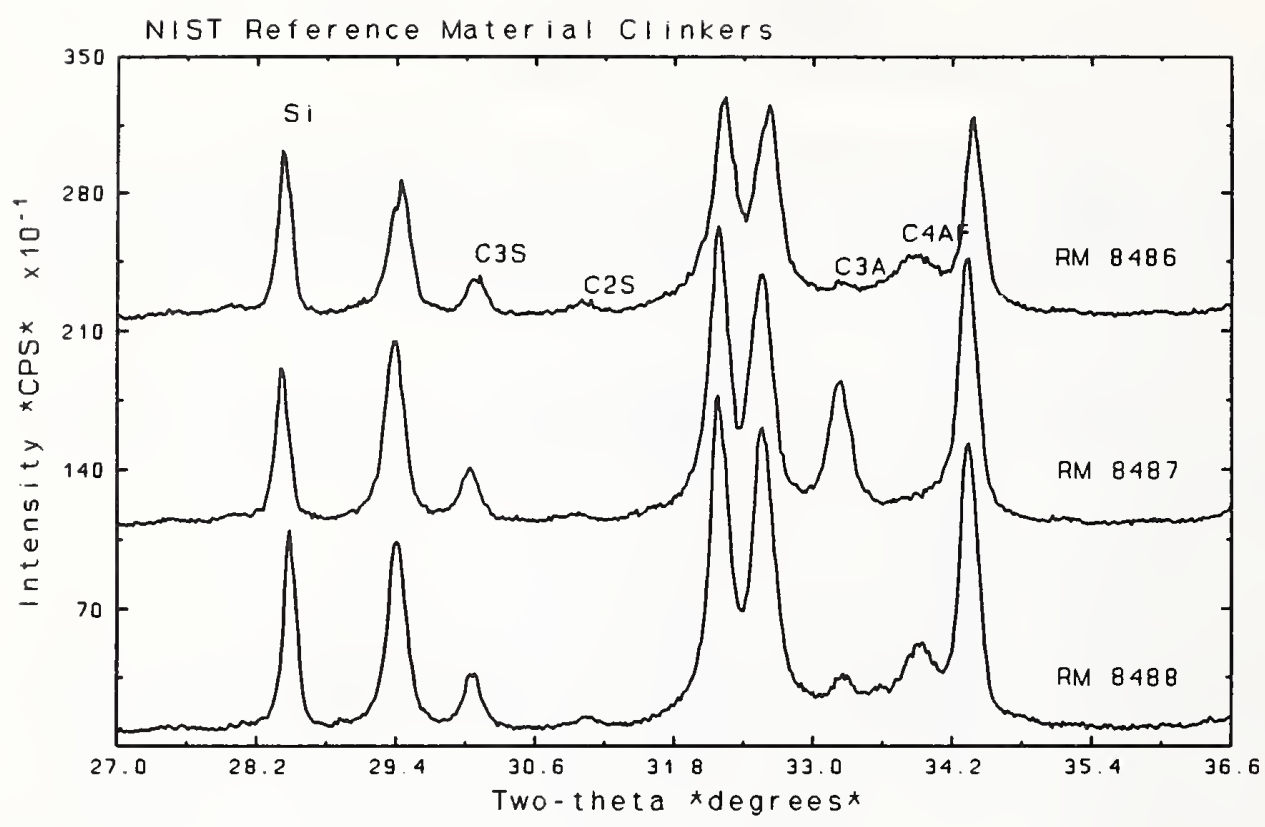

Figure 2. X-ray powder diffraction patterns from RMs 8486 , 8487 , and 8488 .

The program SHADOW ${ }^{3}$ was used for profile fitting, and the pseudoVoight profile shape function provided the best fit to the clinker diffraction peaks. Profile fitting (Figure 3 ) fits a profile to the raw diffraction data, estimates a background, and separates overlapping peaks. It determines the area under the profile after minimizing the differences between the raw data and calculated profiles, thereby producing a background-subtracted peak area using the calculated profiles. The ability to run SHADOW in batch mode facilitated rapid and reproducible peak area measurements.

Figure 3 also illustrates some potential errors in the use of profile fitting for peak area determination. Cement clinker diffraction patterns are complex, exhibiting many partial to complete peak overlaps. Profile fitting is helpful in resolving partially overlapped peaks or peak groups as seen in Figure 3 , but peaks such as the $32.2^{\circ}$ and $32.5^{\circ}$ fit as single peaks are actually multiple peaks from both $\mathrm{C}_{3} S$ and $\mathrm{C}_{2} \mathrm{~S}$. These peaks were not used in this study.

Sample homogeneity problems can be identified by low precision in peak intensities from replicate scans from repacked sample mounts. Based on mass absorption coefficients (about 90 for $C_{3} S$ and $C_{2} S, 100$ to 180 for $C_{4} A F$ depending on composition, 85 for $C_{3} A$, and 28 for $\mathrm{MgO})$, the diffracted beam emanates from approximately the top $35 \mu \mathrm{m}$ of the packed clinker powder. An extremely fine particle size is desirable since a greater number of particles, ideally of different phases, are then present in the volume of powder.

${ }^{3}$ Materials Data, Inc., Livermore, CA. 


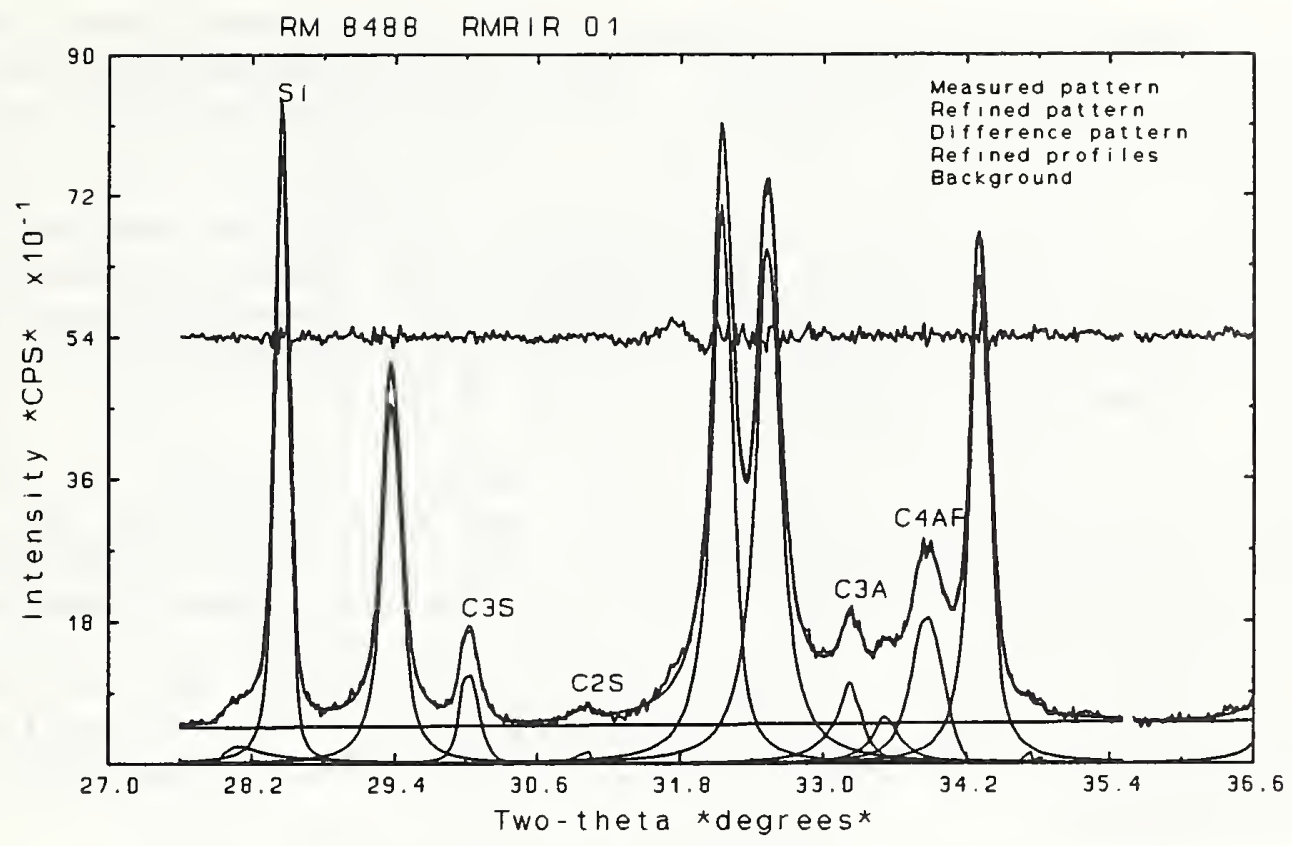

Figure 3. Profile fitting for the determination of backgroundsubtracted peak areas for labeled peaks of the silicon internal standard, $\mathrm{C}_{3} \mathrm{~S}, \mathrm{C}_{2} \mathrm{~S}, \mathrm{C}_{3} \mathrm{~A}$, and $\mathrm{C}_{4} \mathrm{AF}$.

Preferred orientation can be recognized through variation in relative peak intensities of peaks produced by one phase from replicate scans. Finely powdered samples and careful use of either the back-loaded mounting method (used in this study) or sidedrifted mounting method minimize preferred orientation $[5,6]$.

Microabsorption and extinction problems result in incorrect peak intensities. The apparent concentration of $\mathrm{C}_{4} \mathrm{AF}$, with a relatively high mass absorption coefficient, will be greater in coarsegrained powders (greater than $10 \mu \mathrm{m}$ ) due to microabsorption effects. Particle sizes of less than $10 \mu \mathrm{m}$ minimize problems due to microabsorption. Extinction effects arise from destructive interference of the primary beam with the diffracted beam [4]. since most of the diffraction peaks used in these analyses are weak, problems from extinction should be minimal [4].

\subsubsection{The Internal Standard or Reference Intensity Ratio Method for QXRD}

The RM cement clinkers are composite samples of more than four phases, each with a different chemical composition and therefore a different level of X-ray absorption. While the peak intensities are roughly proportional to the abundance of a phase in a mixture, 
the peak intensity-concentration relationship is not linear because of phase and sample absorption. Klug and Alexander [5] show that an absorption correction can be made by use of an internal standard and calibration curves.

The internal standard is a phase not present in the sample that is added to the mixture in a known proportion. With the addition of a known amount of internal standard, the concentration of the unknown phase can be related to the peak intensity ratio of the unknown and internal standard.

The Reference Intensity Ratio (RIR) method utilizes an internal standard for QXRD and the RIR is a constant relating the X-ray scattering power of a phase to that of the internal standard $[7,8]$. The RIR is defined as the ratio of the strongest peak of the unknown phase to that of an internal standard in a one-to-one mixture $[7,8]$. Because of the severe overlapping of the stronger peaks of clinker phases, RIRs for this study were determined for the strongest non-overlapped peaks or peaks that were resolved by profile fitting.

\subsubsection{Selection of an Internal Standard}

The ideal internal standard should not produce diffraction peaks interfering with peaks from phases in the sample, and should be an easily obtainable, stable, pure material with a fine ( $1 \mu \mathrm{m}-10 \mu \mathrm{m})$ particle size, and low susceptibility to orientation [5]. Some previous QXRD studies of cement clinker and cement have used silicon $[3,9,10]$, rutile $[11,12,13]$, potassium bromide [14], cerium oxide [15] and corundum [1] as an internal standard. Silicon, rutile, and $\alpha$-alumina X-ray diffraction standards are available from the standard Reference Materials Program at NIST. This study used NIST SRM 640, silicon powder, as the internal standard.

\subsubsection{Clinker Calibration Standards}

Selection of standards representative of the unknown samples is important for obtaining correct calibrations. Gutteridge [12] illustrated the variability of diffraction peak positions and intensities for $a$ number of $c_{3}$ s polymorphs. Significant RIR differences due to compositional variations in other, natural minerals have been reported by Bish and Chipera [6]. Means of obtaining standards include purchase of commercially available pure compounds, selective extraction of phases from the unknown samples, laboratory synthesis of polymorphs and use of separate calibration curves, and calibration from a bulk sample of known phase abundance composition.

Calibration mixtures are not restricted to equally proportioned binary mixtures but, as demonstrated by chung [7], can be multiphase mixtures of known phase abundance composition. Bish and Snyder [16] found that multiple calibration mixtures using different phase-to-standard ratios provided more accurate RIRs, 
while the use of multiple peaks for each phase minimized effects of preferred orientation.

Therefore for the RIRs used in this study, pure phase calibration mixtures were blended at 50:50 and 80:20 phase-to-standard proportions using phases synthesized at construction Technology Laboratories. Information on synthesis of pure phases can be found in [17]. Additional calibrations $\left(C_{3} S, C_{2} S\right.$, and $\left.C_{4} A F\right)$ were made using well-characterized subsamples of the RM clinker reserve material. About $25 \mathrm{~g}$ of each clinker was split providing samples for QXRD and two polished samples for SEM point count analysis (Table 2).

For the point count analysis, the half width of an approximately 95 percent confidence interval were calculated from eqn. 1:

$$
E_{95.4}=2 \sqrt{\frac{P(100-P)}{N}}
$$

where: $E=$ the half width in percent,

$\mathrm{N}=$ the total number of points or grains counted, and $P=$ the percentage of the phase:

Phase abundance values from the point count (Table 2) were converted to mass percent values using the density using eqn. 2 :

$$
W_{A}=\frac{V_{A} * P_{A} \times 1008}{\Sigma\left[V_{X} * P_{X}\right]}
$$

where: $\quad \mathrm{W}_{\mathrm{A}}=$ Mass percent of phase $\mathrm{A}$

$$
\begin{aligned}
\mathrm{V}_{\mathrm{A}} & =\text { Volume percent of phase } \mathrm{A} \\
\mathrm{P}_{\mathrm{A}} & =\text { Density of phase } \mathrm{A} \\
\Sigma\left(\mathrm{V}_{\mathrm{X}} \star \mathrm{P}_{\mathrm{X}}\right) & =\text { Sum of products for all phases }
\end{aligned}
$$

The QXRD split was blended with internal standard with clinker-tostandard proportions of $80: 20$ and 91:9. The composite sample was wetted with ethanol to make a slurry and blended with the assistance of a high-power ultrasonic probe. A second homogenization of the dried powder by mortar and pestle improved peak intensity reproducibility.

RIR calibration samples were backloaded against a frosted glass plate in a standard $16 \mathrm{~mm}$ by $20 \mathrm{~mm}$ cavity mount. Data scans encompassed a $2 \theta$ range to include all peaks of interest at a scan rate of 2 seconds per $0.02^{\circ}(2 \theta)$ step. Peak intensity ratios from four replicate scans, with the sample repacked for each scan, were averaged to establish the calibration. 
Table 2. Mass percent phase abundance and probable error of SEM point counts for RIR calibrations.

\begin{tabular}{|c|c|c|c|c|c|c|}
\hline & $\mathrm{C}_{3} \mathrm{~s}$ & $\mathrm{C}_{2} \mathrm{~s}$ & $C_{3} \mathrm{~A}$ & $\mathrm{C}_{4} \mathrm{AF}$ & Mgo & CaO \\
\hline $\begin{array}{l}\text { Density } \\
\mathrm{g} / \mathrm{ml}\end{array}$ & 3.15 & 3.73 & 3.58 & 3.73 & 3.58 & 3.34 \\
\hline $\begin{array}{l}\text { RM } \mathbf{8 4 8 8} \\
1600 \\
\text { points }\end{array}$ & $\begin{array}{l}60.8 \\
\pm 2.4\end{array}$ & $\begin{array}{l}17.7 \\
\pm 1.9\end{array}$ & $\begin{array}{r}4.9 \\
\pm 1.1\end{array}$ & $\begin{array}{l}15.9 \\
\pm 1.7\end{array}$ & $\begin{array}{r}0.7 \\
\pm 0.4\end{array}$ & 3.2 \\
\hline $\begin{array}{l}\text { RM } \mathbf{8 4 8 7} \\
1000 \\
\text { points }\end{array}$ & $\begin{array}{l}66.7 \\
\pm 3.9\end{array}$ & $\begin{array}{r}7.3 \\
\pm 2.3\end{array}$ & $\begin{array}{l}18.2 \\
\pm 3.4\end{array}$ & $\begin{array}{r}4.7 \\
\pm 1.7\end{array}$ & 0.0 & 3.2 \\
\hline $\begin{array}{l}\text { RM } 8486 \\
540 \\
\text { points }\end{array}$ & $\begin{array}{l}52.7 \\
\pm 3.1\end{array}$ & $\begin{array}{l}21.0 \\
\pm 2.6\end{array}$ & $\begin{array}{r}2.8 \\
\pm 1.1\end{array}$ & $\begin{array}{l}17.0 \\
\pm 2.1\end{array}$ & $\begin{array}{r}6.5 \\
\pm 1.4\end{array}$ & 0.0 \\
\hline
\end{tabular}

2.4.4 Determination of RIR Values

RIR values (Table 3) were calculated using eqn. 3:

$$
K_{i \alpha}=\frac{I_{i \alpha}}{I_{j S i}} \times \frac{X_{S i}}{X_{\alpha}}
$$

where: $K_{i \alpha}=$ RIR for peak $i$ of phase alpha,

$I_{i \alpha}=$ Peak intensity (area) of peak $i$ of phase alpha,

$I_{j S i}=$ Peak intensity (area) of peak $j$ of the internal standard, silicon,

$\mathrm{X}_{\mathrm{Si}}=$ Concentration of internal standard in the composite sample and,

$\mathrm{x}_{\alpha}=$ Concentration of phase alpha in the composite sample 
Table 3. Reference Intensity Ratios $\left(I / I_{\mathrm{Si}}\right)$ as calculated from the RM clinkers and pure phases. Some peaks used only pure phase RIRs (P); blanks indicate peaks not measured for analysis.

\begin{tabular}{|l|l|c|c|c|l|}
\hline PEAR 2 & PHASE & RM 8486 & RM 8487 & RM 8488 & $\begin{array}{l}\text { Pure } \\
\text { Phase }\end{array}$ \\
\hline 12.16 & $C_{4} \mathrm{AF}$ & 0.0339 & 0.0339 & 0.0367 & 0.0536 \\
\hline 21.05 & $\mathrm{C}_{3} \mathrm{~A}$-Cubic & --- & $\mathrm{P}$ & --- & 0.0171 \\
\hline 21.84 & $\mathrm{C}_{3} \mathrm{~A}$-Cubic & $\mathrm{P}$ & $\mathrm{P}$ & $\mathrm{P}$ & 0.0344 \\
\hline 22.95 & $\mathrm{C}_{3} \mathrm{~S}$ & 0.0108 & 0.0090 & 0.0111 & 0.0121 \\
\hline 24.36 & $\mathrm{C}_{4} \mathrm{AF}$ & $\mathrm{P}$ & $\mathrm{P}$ & $\mathrm{P}$ & 0.0281 \\
\hline 25.14 & $\mathrm{C}_{3} \mathrm{~S}$ & 0.0054 & 0.0066 & 0.0052 & 0.0068 \\
\hline 30.01 & $\mathrm{C}_{3} \mathrm{~S}$ & 0.0249 & 0.0455 & 0.0340 & 0.0344 \\
\hline 31.02 & $\mathrm{C}_{2} \mathrm{~S}-\beta$ & 0.0212 & 0.0371 & 0.0316 & 0.0281 \\
\hline 33.2 & $\mathrm{C}_{3} \mathrm{~A}$ & $\mathrm{P}$ & $\mathrm{P}$ & $\mathrm{P}$ & 0.5420 \\
\hline 35.26 & $\mathrm{C}_{2} \mathrm{~S}-\beta$ & 0.0082 & --- & 0.0188 & 0.0182 \\
\hline 36.77 & $\mathrm{C}_{2} \mathrm{~S}-\beta$ & 0.0750 & 0.1671 & 0.0550 & 0.0370 \\
\hline 37.33 & $\mathrm{C}_{2} \mathrm{~S}-\beta$ & 0.0381 & $\mathrm{P}$ & 0.0350 & 0.0398 \\
\hline 42.9 & $\mathrm{MgO}$ & $\mathrm{P}$ & $\mathrm{P}$ & $\mathrm{P}$ & 0.9779 \\
\hline 56.1 & $\mathrm{C}_{3} \mathrm{~S}$ & 0.1688 & 0.1733 & 0.1842 & 0.1771 \\
\hline
\end{tabular}

2.4.5 QXRD of the RM Clinkers

With the calibration RIRs available, analysis of the unknowns involved the following sequence of steps:

(1) powdering the clinker to $-10 \mu \mathrm{m}$,

(2) addition and homogenization of a known amount of internal standard forming a composite sample,

(3) collect replicate diffraction patterns, repacking the powder for each scan,

(4) measure the peak areas of the internal standard and clinker phases,

(5) calculate phase abundances by averaging the results from the replicate diffraction patterns. 
Addition of six percent by weight silicon powder to the powdered clinker resulted in a composite sample (clinker plus internal standard) with 5.66 percent silicon. The sample was homogenized using the ultrasonic probe and mortar and pestle as described earlier.

Diffraction scans of the RM clinkers were made from 10 to $54^{\circ}$ (20) with a two second count time per $0.02^{\circ}$ (20) step. The concentration of phase alpha in the composite sample is given by eqn. 4:

$$
X_{\alpha}=\frac{I_{i \alpha}}{I_{j S i}} \times \frac{X_{S i}}{R I R_{i, \alpha}}
$$

The concentration of the phase in the original sample is given by eqn. 5 :

$$
X_{\alpha}=X_{\alpha} /\left(1-X_{S i}\right)
$$

\subsection{RESULTS}

Peak intensity variations due to heterogeneity of the composite sample, preferred orientation, and the difficulty in accurate measurement of very weak peaks contribute to the imprecision of the QXRD data. Examination of the QXRD data from replicate scans (Table 4) provides estimates of the precision of this QXRD method and illustrates the necessity of averaging values from multiple scans. The sample standard deviation (STDS) is a measure of how close the values lie to the mean of the distribution. Data in Table $4 \mathrm{a}$ is from replicate scans of the same sample mount, without repacking the powder for each scan. The reported weight percentages reflect the variations in peak intensities in the replicate scans resulting from data collection and measurement of the peak areas. Variations in weight percentages in replicate scans of samples repacked for each scan (Table $4 \mathrm{~b}$ ) are greater for most phases. These replicates additionally include the effects of sample heterogeneity and variations in particle orientation.

Results of the QXRD analyses of the RM clinkers with sample set averages and sample standard deviations are given in Tables 5, 6, and 7, duplicate splits of each sample are designated A and B. Data from earlier studies $[2,18,19]$ is provided for comparison. In general, the values are in agreement with those of previous studies. The inter-sample standard deviation values are generally equal to or less than standard deviations of replicate scans indicating that the precision of the analysis was high. 
Table 4. QXRD Data from replicate scans of sample 1, split A from RM 8486, without repacking the powder (a) and replicate scans after repacking the powder for each scan (b). Weight percent values in (a) reflect peak intensity variations due to data collection and processing while (b) additionally includes variations due to sample heterogeneity and particle orientation.

(A)

\begin{tabular}{|l|c|c|c|c|c|c|}
\hline \hline Phase & Scan 1 & Scan 2 & Scan 3 & Scan 4 & Average & STDS $^{*}$ \\
\hline$C_{3}$ S & 61.26 & 56.70 & 55.53 & 56.78 & 57.28 & 1.98 \\
\hline$C_{2}$ S & 22.98 & 18.37 & 20.16 & 17.69 & 18.79 & 1.04 \\
\hline$C_{4}$ AF & 8.51 & 9.47 & 12.42 & 11.48 & 11.08 & 1.23 \\
\hline$C_{3} A$ & 1.43 & 1.09 & 3.69 & 2.65 & 2.22 & 1.19 \\
\hline MgO & 3.91 & 5.45 & 7.26 & 5.98 & 5.65 & 1.70 \\
\hline
\end{tabular}

(B)

\begin{tabular}{||l|c|c|c|c|c|c|c||}
\hline Phase & Scan 1 & Scan 2 & Scan 3 & Scan 4 & Average & STDS & RM-STDS $^{\circ}$ \\
\hline$C_{3}$ S & 61.26 & 60.34 & 66.57 & 65.47 & 63.41 & 3.07 & 7.55 \\
\hline$C_{2}$ S & 22.98 & 23.67 & 24.27 & 25.01 & 23.98 & 0.86 & 5.16 \\
\hline$C_{4}$ AF & 8.51 & 8.45 & 10.84 & 10.21 & 9.50 & 1.21 & 2.29 \\
\hline$C_{3} A$ & 1.43 & 2.15 & 1.85 & 1.38 & 1.70 & 0.37 & 1.15 \\
\hline MgO & 3.91 & 3.88 & 4.26 & 3.97 & 4.01 & 0.17 & 0.69 \\
\hline
\end{tabular}

* - Sample standard deviation (STDS) is a measure of the spread of values about the mean.

** - Sample standard deviation for all 64 replicates of RM set 3 . 
Table 5. QXRD data for Reference Material Clinker 8486 with optical microscopy point count data (OM) and QXRD data from $[2,3]$, QXRD data from [18], and an SEM point count of one sample [19]. Sample designation $31 \mathrm{~A}$ indicates $\mathrm{RM}$ set $\underline{3}$, sample $\underline{1}$, and duplicate $\underline{\underline{A}}$.

\begin{tabular}{|c|c|c|c|c|c|c|}
\hline Sample & $c_{3} 8$ & $c_{2} s$ & $\mathrm{C}_{4} \mathrm{AF}$ & $\mathrm{C}_{3} \mathrm{~A}$ & MgO & SUM \\
\hline $\begin{array}{l}31 \mathrm{~A} \\
31 \mathrm{~B} \\
\end{array}$ & $\begin{array}{l}63.4 \\
57.5 \\
\end{array}$ & $\begin{array}{l}24.0 \\
22.6 \\
\end{array}$ & $\begin{array}{l}9.5 \\
9.7 \\
\end{array}$ & $\begin{array}{l}1.7 \\
1.7 \\
\end{array}$ & $\begin{array}{l}3.5 \\
3.5 \\
\end{array}$ & $\begin{array}{r}102.6 \\
95.0 \\
\end{array}$ \\
\hline $\begin{array}{l}32 \mathrm{~A} \\
32 \mathrm{~B}\end{array}$ & $\begin{array}{l}58.3 \\
64.0 \\
\end{array}$ & $\begin{array}{l}26.4 \\
18.7 \\
\end{array}$ & $\begin{array}{l}7.6 \\
7.7 \\
\end{array}$ & $\begin{array}{l}1.8 \\
1.6 \\
\end{array}$ & $\begin{array}{l}3.5 \\
3.5\end{array}$ & $\begin{array}{l}97.6 \\
95.5\end{array}$ \\
\hline $\begin{array}{l}33 \mathrm{~A} \\
33 \mathrm{~B}\end{array}$ & $\begin{array}{l}59.1 \\
61.8\end{array}$ & $\begin{array}{l}15.9 \\
16.5\end{array}$ & $\begin{array}{l}13.3 \\
13.3\end{array}$ & $\begin{array}{l}2.6 \\
3.0 \\
\end{array}$ & $\begin{array}{l}4.1 \\
4.9\end{array}$ & $\begin{array}{l}95.0 \\
99.5\end{array}$ \\
\hline $\begin{array}{l}34 \mathrm{~A} \\
34 \mathrm{~B} \\
\end{array}$ & $\begin{array}{l}55.2 \\
59.2 \\
\end{array}$ & $\begin{array}{l}17.4 \\
15.1 \\
\end{array}$ & $\begin{array}{l}10.6 \\
12.3 \\
\end{array}$ & $\begin{array}{l}2.6 \\
4.0 \\
\end{array}$ & $\begin{array}{l}4.0 \\
4.5 \\
\end{array}$ & $\begin{array}{l}89.8 \\
95.1 \\
\end{array}$ \\
\hline $\begin{array}{l}35 \mathrm{~A} \\
35 \mathrm{~B} \\
\end{array}$ & $\begin{array}{l}58.9 \\
64.2 \\
\end{array}$ & $\begin{array}{l}13.3 \\
13.9 \\
\end{array}$ & $\begin{array}{l}12.5 \\
13.0 \\
\end{array}$ & $\begin{array}{l}3.6 \\
3.3 \\
\end{array}$ & $\begin{array}{l}4.6 \\
4.8 \\
\end{array}$ & $\begin{array}{l}92.9 \\
99.2 \\
\end{array}$ \\
\hline $\begin{array}{l}36 \mathrm{~A} \\
36 \mathrm{~B}\end{array}$ & $\begin{array}{l}57.9 \\
59.9\end{array}$ & $\begin{array}{l}11.6 \\
11.2\end{array}$ & $\begin{array}{l}12.9 \\
12.4\end{array}$ & $\begin{array}{l}2.8 \\
2.2\end{array}$ & $\begin{array}{l}4.4 \\
4.5\end{array}$ & $\begin{array}{l}89.6 \\
90.2\end{array}$ \\
\hline $\begin{array}{l}37 \mathrm{~A} \\
37 \mathrm{~B} \\
\end{array}$ & $\begin{array}{l}64.4 \\
65.7 \\
\end{array}$ & $\begin{array}{l}12.2 \\
13.2 \\
\end{array}$ & $\begin{array}{l}13.1 \\
12.5 \\
\end{array}$ & $\begin{array}{l}3.8 \\
3.6 \\
\end{array}$ & $\begin{array}{l}5.1 \\
5.1 \\
\end{array}$ & $\begin{array}{r}98.6 \\
100.1 \\
\end{array}$ \\
\hline $\begin{array}{l}38 \mathrm{~A} \\
38 \mathrm{~B} \\
\end{array}$ & $\begin{array}{l}61.2 \\
62.8 \\
\end{array}$ & $\begin{array}{l}17.5 \\
21.3 \\
\end{array}$ & $\begin{array}{l}12.8 \\
12.4 \\
\end{array}$ & $\begin{array}{l}2.7 \\
4.0 \\
\end{array}$ & $\begin{array}{l}4.6 \\
4.8 \\
\end{array}$ & $\begin{array}{r}98.8 \\
105.3 \\
\end{array}$ \\
\hline $\begin{array}{l}\text { Avg. } \\
\text { STDS }\end{array}$ & $\begin{array}{r}60.8 \\
3.0 \\
\end{array}$ & $\begin{array}{r}16.9 \\
4.6 \\
\end{array}$ & $\begin{array}{r}11.6 \\
1.9 \\
\end{array}$ & $\begin{array}{l}2.8 \\
0.8 \\
\end{array}$ & $\begin{array}{l}4.4 \\
0.5 \\
\end{array}$ & 96.5 \\
\hline $\begin{array}{l}\text { OM }[2,3] \\
\text { QXRD [2,3] } \\
\text { QXRD [18] } \\
\text { SEM [19] }\end{array}$ & $\begin{array}{l}58.5 \\
57.0\end{array}$ & $\begin{array}{l}23.2 \\
23.0\end{array}$ & $\begin{array}{l}13.7 \\
11.1 \\
12.9 \\
15.0\end{array}$ & $\begin{array}{l}1.2 \\
4.7 \\
4.0 \\
1.0\end{array}$ & $\begin{array}{l}3.2 \\
3.4 \\
3.0 \\
4.0\end{array}$ & \\
\hline
\end{tabular}


Table 6. QXRD data for Reference Material Clinker 8487, with optical microscopy point count (OM) and QXRD data from $[2,3]$, QXRD data from $[18]$, and SEM point count data of one sample from [19].

\begin{tabular}{|l|l|l|l|l|l|l||}
\hline sample & $C_{3} s$ & $C_{2} s$ & $C_{4} A F$ & $C_{3} A$ & MgO & sUM \\
\hline 21A & 72.2 & 11.8 & 3.4 & 12.9 & 0.8 & 101.2 \\
21B & 62.2 & 10.7 & 3.5 & 10.9 & 0.8 & 88.0 \\
\hline 22A & 69.9 & 11.8 & 3.1 & 11.6 & 0.9 & 97.3 \\
22B & 69.3 & 11.8 & 2.1 & 10.5 & 0.9 & 94.6 \\
\hline 23A & 70.0 & 11.9 & 1.5 & 10.1 & 0.9 & 94.4 \\
23B & 67.7 & 10.0 & 2.5 & 11.5 & 0.9 & 92.6 \\
\hline 27A & 66.9 & 11.4 & 2.9 & 11.7 & 0.8 & 93.7 \\
27B & 64.3 & 9.3 & 2.3 & 11.2 & 0.7 & 87.8 \\
\hline 25A & 71.5 & 10.6 & 3.0 & 12.7 & 0.8 & 98.7 \\
25B & 72.3 & 12.5 & 2.7 & 12.4 & 0.0 & 100.9 \\
\hline 26A & 59.9 & 12.3 & 2.4 & 10.0 & 0.6 & 85.2 \\
26B & 67.7 & 12.7 & 2.3 & 11.4 & 0.8 & 94.9 \\
\hline 27A & 68.3 & 9.7 & 2.8 & 12.0 & 0.8 & 93.6 \\
27B & 66.2 & 9.2 & 2.4 & 10.8 & 0.8 & 89.4 \\
\hline 23A & 66.3 & 10.4 & 2.2 & 10.9 & 0.8 & 90.5 \\
23B & 65.5 & 10.8 & 3.2 & 11.0 & 0.7 & 91.2 \\
\hline Average & 67.5 & 11.1 & 2.7 & 11.4 & 0.8 & 100.5 \\
STDS & 3.5 & 1.3 & 0.5 & 0.9 & 0.1 & \\
\hline OM [2,3] & 73.4 & 7.8 & 3.3 & 12.1 & 0.1 & \\
QXRD [2,3] & & & 2.1 & 11.3 & 0.3 & \\
QXRD [18] & 70.0 & 3.0 & 3.3 & 21.0 & 0.0 & \\
SEM [19] & & & & & & \\
\hline
\end{tabular}


Table 7. QXRD data for Reference Material 8488, with optical microscopy point count (OM) and QXRD data from [2,3], QXRD data from [18], and SEM point count data of one sample from [19].

\begin{tabular}{|l|l|l|l|l|l||}
\hline Sample & $C_{3} \mathrm{~S}$ & $\mathrm{C}_{2} \mathrm{~S}$ & $\mathrm{C}_{4} \mathrm{AF}$ & $\mathrm{C}_{3} \mathrm{~A}$ & SUM \\
\hline 11A & 69.8 & 16.9 & 13.8 & 4.4 & 104.9 \\
11B & 63.0 & 16.9 & 14.1 & 6.4 & 100.4 \\
\hline 12A & 61.3 & 16.6 & 14.9 & 4.8 & 97.6 \\
12B & 65.9 & 17.7 & 16.5 & 7.0 & 107.1 \\
\hline 13A & 61.5 & 17.4 & 15.7 & 5.8 & 100.4 \\
13B & 62.9 & 18.7 & 13.6 & 4.9 & 100.1 \\
\hline 14A & 68.0 & 17.7 & 15.8 & 6.8 & 107.6 \\
14B & 61.1 & 16.2 & 14.7 & 6.2 & 96.8 \\
\hline 15A & 61.3 & 17.5 & 13.8 & 6.0 & 98.6 \\
15B & 58.4 & 15.9 & 14.5 & 4.0 & 92.8 \\
\hline 18A & 65.1 & 16.9 & 16.9 & 6.8 & 106.8 \\
18B & 57.2 & 16.9 & 16.9 & 6.2 & 92.7 \\
\hline 12A & 69.3 & 16.7 & 15.5 & 5.8 & 106.8 \\
12B & 60.0 & 15.4 & 13.7 & 8.9 & 95.1 \\
\hline 18A & 63.5 & 17.9 & 15.2 & 5.1 & 101.7 \\
18B & 58.6 & 13.6 & 13.3 & 6.2 & 91.7 \\
\hline Average & 62.9 & 16.7 & 14.8 & 5.8 & 100.1 \\
STDS & 3.8 & 1.4 & 1.1 & 6.9 & \\
\hline OM [2,3] & 65.0 & 18.5 & 12.1 & 4.3 & \\
QXRD [2,3] & & & 11.6 & 4.4 & \\
QXRD [18] & 62.0 & 22.0 & 13.5 & 5.5 & \\
SEM [19] & 62.0 & 5.0 & \\
\hline
\end{tabular}

Discrepancies between QXRD and optical data exist for matrix phases $\mathrm{C}_{4} \mathrm{AF}$, and $\mathrm{C}_{3} \mathrm{~A}$. Because of their fine particle size these phases are probably the most difficult to quantify by optical microscopy $[2,3]$. Separate analysis of SAM residues where these phases are concentrated may help in their analysis. Differences in $C_{2} S$ values for RM 8486 may reflect the heterogeneity of $C_{2} S$ within the clinker. 


\subsection{DISCUSSION}

QXRD analysis of cement clinker is difficult because of the complex diffraction patterns and numerous peak overlaps. Selection of weak peaks for calibration is necessary because of these overlaps, making accurate measurement of peak intensities very important. Use of a two second step time in data collection reduced noise, though data collection times were about 1.3 hours. Profile fitting provided peak areas, consistency in background estimation, and resolved most overlapped peaks. Batch processing of the diffraction data made multiple-peak calibrations and analyses simpler. Use of multiple peaks is recommended to minimize orientation effects.

Use of a well characterized subsample from each of the RM clinkers for calibrations was used to address a common QXRD problem, that of matching the standards to the samples. As mentioned earlier, Gutteridge [12] illustrated the variability of peak positions and relative intensities of different polymorphs. Use of a single, laboratory-synthesized pure phase may not be representative of that phase in the unknowns resulting in an inaccurate calibration. Examination of the RIRs for different peaks shows that while some of the differences are very small, differences do exist for other peaks. These differences probably reflect structural and chemical differences between the pure-phase and the industrial clinker standards.

\subsection{SUMMARY}

Quantitative X-ray powder diffraction data was collected from randomly selected samples of the NIST Reference Material clinkers. Phase abundance values generally agreed with those reported in earlier studies and inter-sample standard deviation values were generally less than or equal to the intra-sample standard deviation values. The ability to accurately and rapidly determine the phase abundances in a cement clinker will aid in the correlation of clinker phase composition with performance and durability properties of cement and concrete. The NIST Reference Material clinkers can be used to test and develop methods of quantitative phase abundance analysis.

\subsection{ACKNOWLEDGEMENTS}

This work was supported by the office of standard Reference Materials at NIST under Program managers Mr. Tom Gills and Ms. Jean Kane. The assistance and recommendations of Dr. Geoffrey Frohnsdorff, Dr. Mary McKnight, Dr. Jim clifton of NIST and Dr. Leslie struble, formerly of NIST and now at the University of Illinois, were appreciated. 


\subsection{REFERENCES}

1. Taylor, H.F.W., Cement Chemistry, Academic Press, New York, 475 pp., 1990.

2. Portland Cement Clinker, National Institute of standards and Technology Report of Investigation, Reference Materials 8486, 8487, 8488 , May 22, 1989.

3. Kanare, H.M., Production of Portland Cement Clinker Phase Abundance Standard Reference Materials. Construction Technology Laboratories Project No. CRA012-840, 32 pp., Dec. 8, 1987.

4. Bish, D.L. and Reynolds, R.C. Jr., Sample Preparation for X-Ray Diffraction. Reviews in Mineralogy, D.L. Bish and J.E. Post, eds., Vol. 20, pp. 73-99, 1989.

5. Klug, H.P., and Alexander, L.E., X-Ray Diffraction Procedures, John Wiley and Sons, New York, 1974.

6. Bish, D.L., and Chipera, S.J., Problems and Solutions in Quantitative Analysis of Complex Mixtures by X-ray Powder Diffraction. Advances in X-Ray Analysis, 31, pp. 295-308, 1988.

7. Chung, F.H., Quantitative Interpretation of X-Ray Diffraction Patterns of Mixtures. I. Matrix-Flushing Method for Quantitative Multicomponent Analysis. Jour. Appl. Cryst., 7, pp 519-525, 1974.

8. Hubbard, C.R. and Snyder, R.L., RIR - Measurement and Use in Quantitative XRD. Powder Diffraction, Vol. 3, No. 2, pp. 74-77, 1988 .

9. Kantro, D.L., Copeland, L.E., Weise, C.H., and Brunauer, S., Quantitative Determination of the Major Phases in Portland Cements by X-Ray Diffraction Methods. Journal of the PCA Research and Development Laboratories, 6(1), pp. 20-40, 1964 .

10. Stutzman, P.E., Lenker, S., Kanare, H., Tang, F., Campbell, D., and Struble, L., Standard Cement Clinkers for Phase Analysis. Proc. of the Eleventh International Conference on cement Microscopy, G. Gouda, A. Nisperos, and J. Bayles eds., pp. 154$168,1989$.

11. Aldridge, L.P., Accuracy and Precision of an X-Ray Diffraction Method for Analyzing Portland Cements. Cement and Concrete research, Vol. 12, pp. 437-446, 1982 .

12. Gutteridge, W.A., Quantitative X-Ray Powder Diffraction in the study of Some Cementive Materials. The British Ceramic Society meeting on Chemistry and Chemically-Related Properties of Cement, London, 1984 . 
13. Berger, R.L., Frohnsdorff, G.J.C., Harris, P.H., and Johnson, P.D., Application of X-Ray Diffraction to Routine Mineralogical Analysis of Portland Cement. Highway Research Board Special Report No. 90, pp. 234-253, 1964 .

14. Midgley, H.G., Rosaman, D., and Fletcher, K.E., X-Ray Diffraction Examination of Portland Cement clinker. Fourth International symposium on the chemistry of cement, Washington, D.C., pp. 69-81, 1960 .

15. Howard, B.H., Preliminary Data on QXRD Analysis of Portland Cement and $\mathrm{Clinker} U$ Using $\mathrm{CeO}_{2}$ as the Internal Standard, Cement and Concrete research, Vol. 14, pp. 729-740, 1984.

16. Snyder, R.L. and Bish, D.L., Quantitative Analysis, Reviews in Mineralogy, D.I. Bish and J.E. Post eds., Vol. 20, pp. 101-144, 1989.

17. Struble, L., and H. Kanare, Cooperative Calibration and Analysis of Cement Clinker Phases, NISTIR 89-4164, 44pp., 1989.

18. Struble, L., Quantitative Phase Analysis of Clinker Using Xray Diffraction, Cement and Concrete Aggregates, Vol. 13, No. 2, winter 1991, pp. 97-102.

19. Stutzman, P., Quantitative Phase Abundance Analysis of Three Clinker Reference Materials by Scanning Electron Microscopy, Proc. of the Conference on Advances in Cementitious Materials, July 2226, 1990, American Ceramic Society, pp. 199-210. 

1. PUBLCATION OR REPORT MUMBER

NISTIR 4785

2. PERFORMING ORGANIZATION AEPOAT NUMBEA

3. PUBLICATION DATE

April 1992

TITLEAND SUBTITLE

X-Ray Powder Diffraction Analysis of Three Portland Cement Reference Material Clinkers

AUTHOR(S)

Paul E. Stutzman

PERFORMINO ORGANIZATION (IF JOINT OR OTHER THAN NIST, SEE INSTRUCTIONS)

U.S. DEPAATMENT OF COMMERCE

NATIONAL INSTITUTE OF STANDARDS AND TECHNOLOQY

GAITHERSBURO, MD 20890

7. CONTRACT/GRANT MUMBER

8. TYPE OF REPORT AND PERIOD COVEREO

SPONSORINQ ORQANIZATION MAME AND COMPLETE ADDRESS (STREET. CITY, STATE, ZIP)

SUPPLEMENTAAY NOTES

ABSTRACT (A 200-WORD OR LESS FACTUAL SUMMARY OF MOST SIONIFICANT INFOAMATION. IF DOCUMENT IMCLUDES A SIGNIFICANT BIBLOQRAPHY OA UTERATURE SURVEY, MENTION IT HERE)

Three portland cement clinker Reference Materials (RMs) are now available from the National Institute of Standards and Technology (NIST). They are intended for use in testing and developing methods for quantitative phase abundance analysis and have been selected as representative of the range of compositions and textures of North American clinkers.

Quantitative $x$-ray powder diffraction analysis was used to determine the phase abundance composition and compositional variability of eight randomly selected samples from each RM. In addition, each sample was split for duplicate analyses for evaluation of intra-sample phase abundance variability. The Reference Intensity Ratio method was used for powder diffraction calibrations and quantitative analysis. Both pure-phase standards and subsamples of the RM clinkers, which were point counted using the scanning electron microscope, were used for calibrations. Phase abundance values generaliy agree with those reported in earlier studies and the inter-sample standard deviation values were generally less than or equal to the intra-sample standard deviation values.

KEY WORDS (6 TO 12 ENTRIES; ALPHABETICAL ORDER; CAPITAUZE ONLY PROPER MAMES; AND SEPARATE KEY WORDS BY SEMICOLONS)

Cement clinker; composition; optical microscopy; quantitative analysis; reference materials; scanning electron microscopy; X-ray powder diffraction

\section{AVAILABIUTY}

$\mathrm{X}$ UNLMITED

FOR OFFICIAL DISTRIBUTION. DO NOT RELEASE TO MATIONAL TECHMICAL INFORMATION SERVICE (NTIS).

ORDER FROM SUPERINTEMDENT OF DOCUMENTS, U.S. GOVERNMENT PRINTINQ OFFICE, WASMINGTON, DC 20402.

ORDER FROM MATIONAL TECHMICAL INFORMATION SERVICE (NTIS), SPRINGFIELD, VA 22161.

14. MUMBER OF PAINTED PAGES

25

15. PRICE $\mathrm{A} 02$ 


